\title{
How Age of Transplants from In Vitro Derived Potato Plantlets Affects Crop Growth and Seed Tuber Yield After Field Transplanting
}

\author{
W. J. M. Lommen ${ }^{1}$ \\ Received: 21 September 2015 / Accepted: 3 November 2015 / \\ Published online: 11 December 2015 \\ (C) The Author(s) 2015. This article is published with open access at Springerlink.com
}

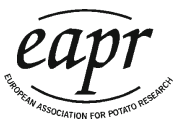

\begin{abstract}
In vitro produced plantlets are used in potato seed systems for production of minitubers under protected conditions or for production of transplants to be transplanted to the field. Three field experiments were carried out to analyse how transplant age (Age) affected the field performance. In the main experiments, 2-, 3- and 4-week-old transplants of the very early cultivar Gloria (Exp. 1) and the mid-early cultivar Bintje (Exp. 2) were produced in a glasshouse. Exp. 3 was a check experiment in which 2- and 3-week-old transplants of cv. Gloria were produced in growth chambers under conditions that were non-inductive for tuberization (24-h photoperiod, high temperature). Ground cover (GC) was assessed weekly and weights of the tuber and canopy fractions were assessed at 0, 14, 28, 42, 56, 70 and 84 days after transplanting (DAT). Yield analysis [accumulated intercepted radiation (AIR), radiation use efficiency (RUE), total dry weight (TDW), harvest index (HI) and tuber dry matter concentration] was carried out; the fraction dry matter (DM) allocated to the tubers and the canopy was calculated for three 2-week intervals after field transplanting. When raised in the glasshouse, older transplants were more advanced in tuber formation and canopy growth than younger transplants and had a higher GC at transplanting. However, crops from younger transplants produced significantly higher fresh tuber yields than crops from older transplants in the later part of the growing period in Exp. 1; the same trend was observed in Exp. 2. AIR was the most important yield component affected by transplant age; RUE, HI and tuber dry matter concentration were not or not meaningfully affected by transplant age. In the first 2 weeks after field transplanting, a very high percentage of the DM produced ( $>85 \%$ ) was allocated to tuber growth in crops from the oldest transplants. This reduced AIR severely. The results show clearly that seed crops from younger transplants will perform better than crops from older
\end{abstract}

W. J. M. Lommen

willemien.lommen@wur.nl

1 Centre for Crop Systems Analysis, Wageningen University, Droevendaalsesteeg 1, 6708

PB Wageningen, The Netherlands 
transplants or at least perform at par. Implications for transplant production management are discussed.

Keywords Ground cover-Harvest index - In vitro plantlets $\cdot$ LUE $\cdot$ Minitubers $\cdot$ Radiation conversion coefficient - Radiation interception - Radiation use efficiency · Seed production - Transplant age $\cdot$ Tuber formation $\cdot$ Yield formation

$\begin{array}{ll}\text { Abbreviations } \\ \text { AIR } & \text { Accumulated intercepted radiation } \\ \text { DAT } & \text { Days after transplanting } \\ \text { GC } & \text { Ground cover } \\ \text { HI } & \text { Harvest index } \\ \text { RUE } & \text { Radiation use efficiency } \\ \text { TDW } & \text { Total dry weight }\end{array}$

\section{Introduction}

In vitro propagated potato plantlets are well-known sources of healthy propagation material (e.g. Jones 1988; Struik and Lommen 1990; Struik and Wiersema 1999) and have at present a well-established role in seed potato production systems, either by being used for production of minitubers in protected systems (e.g. Ritter et al. 2001; Farran and Mingo-Castel 2006; Struik 2007; van der Veeken and Lommen 2009) or for production of seed tubers in the field. Because direct field planting leads to low survival rates (Levy 1988; Sipos et al. 1988; Li et al. 1990). in vitro propagated plantlets are first raised to transplants before transplanting to the field (e.g. Thornton and Knutson 1986; Mc Cown and Wattimena 1987; Hagman 1990; Struik and Lommen 1990; Tadesse et al. 2001a; b). Proper canopy development after field transplanting is crucial for achieving high yields. Glasshouse-raised transplants from very early cultivars can show an extremely poor field performance (Haverkort et al. 1991a; Dixon 1993; Lommen 1999). This was shown to be caused by the relatively large portion of daily dry matter production immediately after transplanting being invested in tuber growth rather than in haulm growth, in early cultivars (Lommen 1999). this limits haulm growth and later biomass production and greatly reduces final tuber yield.

Transplants from early cultivars already progress considerably to tuber induction and formation while they are produced in the glasshouse (Lommen and Struik 2006). this may explain why they start tuber bulking too early after field planting. Field performance of transplants from early cultivars possibly could be enhanced when the progress to tuber induction and formation is slowed down, for instance by shortening the transplant production period or growing transplants under less inductive conditions (cf. Tadesse et al. 2001a; b). Although shorter transplant production periods have been shown to reduce the degree of tuber induction acquired at the moment of field transplanting (Lommen and Struik 2006). they have not yet been shown to change also the field performance of potato crops.

In this research, effects of duration of the transplant production phase were studied (1) to understand how the age of transplants affects their growth and subsequent tuber yield in the field, and (2) to account for differences based on a yield formation analysis. 
It was expected that crops from older transplants would be more advanced at transplanting (starting with higher ground cover and thus a higher radiation interception and production potential) but may suffer more from the transplanting (leading to a lower radiation conversion efficiency) and might invest relatively more in tuber growth than in canopy growth (resulting in a lower relative increase in canopy weight and ground cover) when compared to crops from younger transplants.

Results will lead to improved understanding and can be used to further improve the transplant production management and commercial minituber production.

\section{Materials and Methods}

Three field experiments were carried out to analyse how transplant age affected the field performance based on underlying growth parameters. In the main experiments (Exps. 1 and 2) 2-, 3- and 4-week-old transplants of the early cultivar Gloria (Exp. 1) and the mid-early cultivar Bintje (Exp. 2) were produced under standard glasshouse conditions. Exp. 3 was a check experiment in which 2- and 3-week-old transplants of cv. Gloria were produced under conditions that were non-inductive for tuberization.

\section{In Vitro Multiplication}

Virus-free in vitro stock plantlets were routinely multiplied by single-node cuttings in culture tubes (one node per tube) on $10 \mathrm{ml}$ medium consisting of basal salts and vitamins according to Murashige and Skoog (1962). $2 \mathrm{mg} \mathrm{l}^{-1}$ glycine, $8 \mathrm{~g} \mathrm{l}^{-1}$ agar, $25 \mathrm{~g} \mathrm{l}^{-1}$ sucrose and $0.0118 \mathrm{~g} \mathrm{l}^{-1}$ daminozide applied as Alar-64, $\mathrm{pH} \mathrm{5.7.} \mathrm{The}$ temperature in the growth room was $23{ }^{\circ} \mathrm{C}$, photoperiod was $16 \mathrm{~h}$, and light was supplied by Philips- 84 fluorescent tubes at $6-8 \mathrm{~W} \mathrm{~m}^{-2}$. The timing of the last multiplication was scheduled in such a way that it took place 3 weeks $(20,21$ and 22 days) before planting for all experimental plants. In this last multiplication phase, medium and culture conditions were the same as for routine multiplication, but Petri dishes containing $20 \mathrm{ml}$ medium were used, and ten nodes were planted per Petri dish.

\section{Transplant Production}

Three-week-old in vitro plantlets $(\sim 2-4 \mathrm{~cm}$ tall) with roots were planted at weekly intervals into transplant trays with cells of $6.0 \times 4.0 \times 5.5 \mathrm{~cm}(l \times w \times d)$ filled with potting soil and were grown for different periods using two types of conditions. In the two main experiments, standard conditions during transplant production were used to produce transplants of 2, 3 and 4 weeks old of cv. Gloria (Exp. 1) and cv. Bintje (Exp. 2). Standard conditions involved growth in a controlled glasshouse at $20 / 8{ }^{\circ} \mathrm{C}$ day/night temperature and 16-h photoperiod and thermoperiod. Production was scheduled in such a way that it ended at the same day for all transplants. In the Check experiment, Exp. 3, transplants of cv. Gloria were produced for 2 or 3 weeks under non-inducing conditions at $26 / 14{ }^{\circ} \mathrm{C}$ day/night temperature and 24-h photoperiod in growth chambers. The photoperiod of $24 \mathrm{~h}$ was provided by continuous incandescent light at low intensity, whereas during 'day time', extra light was applied for $16 \mathrm{~h}$ by a 1:1 mixture of Philips SON-T and HPI lamps, supplemented by fluorescent TL 84 light, providing together $120 \mathrm{~W} \mathrm{~m}^{-2}$. 
In the last 3 days of transplant production, all transplants were hardened outside under ambient conditions (average air temperature at $150 \mathrm{~cm} 16.1{ }^{\circ} \mathrm{C}$, average global radiation $2042 \mathrm{~J} \mathrm{~cm}^{-2}$ day $^{-1}$ ). Plants were watered daily and received a low-dosed complete nutrient solution (Lommen and Struik 1992) twice a week.

\section{Field Growth}

Field transplanting took place on the same day for all transplants. Transplants were planted by hand in 15-cm-high ridges with planting holes of $6 \mathrm{~cm}$ into a light sandy soil in Achterberg, near Wageningen, Netherlands (51 $\left.59^{\prime} \mathrm{N}, 05^{\circ} 35^{\prime} \mathrm{E}\right)$, on 31 May 1995. Spacing was $20 \mathrm{~cm}$ in ridges $75 \mathrm{~cm}$ wide. Fertilizer was broadcast at $120 \mathrm{~kg} \mathrm{~N}^{-1}$, $100 \mathrm{~kg} \mathrm{P}_{2} \mathrm{O}_{5} \mathrm{ha}^{-1}$ and $80 \mathrm{~kg} \mathrm{~K}_{2} \mathrm{O} \mathrm{ha}^{-1} 4$ weeks before transplanting. Extra hilling (1$2 \mathrm{~cm}$ ) in combination with weed control was carried out 27 days after transplanting (DAT). Pest management and irrigation followed standard local practices.

A split-plot design was used, with six sampling dates $(14,28,42,56,70$ and 84 DAT) randomized within a transplant age and with five replicated blocks in all experiments. Net plots contained six plants and were surrounded by one guard row and at least two guard plants within a row. At transplanting, six extra plants per block were harvested from each treatment to determine the status of the transplants at field planting. Experiments were part of a larger experiment not reported on here. Mean air temperature at $10 \mathrm{~cm}$ was $12.2^{\circ} \mathrm{C}$ during the first 2 weeks after field transplanting, and $18.4{ }^{\circ} \mathrm{C}$ during the total field period. Average global radiation during the field period was $1950 \mathrm{~J} \mathrm{~cm}^{-2}$ day $^{-1}$.

\section{Measurements and Statistical Methods}

At the 2-weekly harvests, non-tuber parts (leaves, stems and stolons) were combined in a fraction 'canopy'. Tubers were regarded to be a tuber when having a diameter $>2$ times the stolon diameter. Dry weights of the canopy and tuber fractions were determined after drying the cut material for $24 \mathrm{~h}$ at $105^{\circ} \mathrm{C}$. Only the total number of tubers was assessed and their average weight was calculated.

The percentage of dry matter allocated to canopy or tubers during a specific time interval after field transplanting was derived from the increase in canopy dry matter divided by the increase in canopy + tuber dry matter between two subsequent harvest moments in a main plot.

The fraction ground cover (GC) was estimated weekly using a grid of 100 squares $(90 \times 75 \mathrm{~mm}$ each $)$. Daily GC values were derived by linear intrapolation. Measurements at 1 DAT were assumed to represent GC at transplanting. The daily intercepted global radiation was derived by multiplying the daily global radiation by the fraction GC. Daily global radiation data were derived from a nearby weather station. The accumulated intercepted global radiation (AIR) during the field period was obtained by summarizing daily intercepted radiation values. Harvest index (HI) was the tuber dry weight divided by the total dry weight (TDW) of leaves, stems, stolons and tubers, excluding roots. The 'TDW production during the field period' was the TDW corrected for the weight at transplanting. Radiation use efficiency (RUE) during the field period was the TDW produced during the field period divided by the AIR accumulated during the field period. 
Data were subjected to analysis of variance using Genstat release 16.2 (VSN International Ltd., 2013), and differences between treatments were analysed by LSD tests at $\alpha<0.05$. Effects of transplants age on development of GC, AIR, tuber dry weight, canopy dry weight, TDW and tuber fresh weight (FW) with time after transplanting were analysed after $\ln (x)$ or $\ln (1+x)$ transformation; means were backtransformed for presentation. Effects of transplant age on the development of tuber number with time were analysed after square root transformation of the number of tubers and presented as such.

\section{Results}

\section{Status of the Transplants at the Moment of Field Planting}

At transplanting to the field, younger transplants raised under standard conditions had lower TDW, lower canopy dry weight and smaller GC than older transplants (Table 1), although the difference in canopy dry weight between 3- and 4-week-old transplants of cv. Gloria (Exp. 1) was not statistically significant. Tuber initiation had not yet started in the youngest (2-week-old) transplants (Table 1). The intermediate-age (3-week-old) transplants raised under standard conditions had produced less tuber dry weight and had a lower harvest index (HI) than the oldest (4-week-old) transplants which had already $28 \%$ (cv. Gloria, Exp. 1) and 18\% (cv. Bintje, Exp. 2) of their total dry matter allocated to tubers at the moment of transplanting to the field (Table 1). Tuber number

Table 1 Transplant characteristics at the moment of transplanting to the field and ground cover after transplanting for transplants of different age of cv. Gloria (Exp. 1) and cv. Bintje (Exp. 2) raised under standard glasshouse conditions and for transplants of cv. Gloria raised under non-inducing conditions in growth rooms (Exp. 3)

\begin{tabular}{|c|c|c|c|c|c|c|}
\hline $\begin{array}{l}\text { Age of transplant at field } \\
\text { transplanting }\end{array}$ & $\begin{array}{l}\text { Total DW } \\
\text { mg/plant }\end{array}$ & $\begin{array}{l}\text { Canopy DW } \\
\text { (mg/plant) }\end{array}$ & $\begin{array}{l}\text { Tuber DW } \\
\text { (mg/plant) }\end{array}$ & $\begin{array}{l}\mathrm{HI} \\
(\mathrm{g} / \mathrm{g})\end{array}$ & $\begin{array}{l}\text { Tuber nr } \\
\text { (\#/plant) }\end{array}$ & $\begin{array}{l}\text { Ground } \\
\text { cover }(\%)\end{array}$ \\
\hline \multicolumn{7}{|c|}{ Exp. $1 \mathrm{cv}$. Gloria, standard conditions } \\
\hline 2 weeks & $115 \mathrm{a}$ & $115 \mathrm{a}$ & $0 \mathrm{a}$ & $0.00 \mathrm{a}$ & $0.0 \mathrm{a}$ & $1.7 \mathrm{a}$ \\
\hline 3 weeks & $577 \mathrm{~b}$ & $520 \mathrm{~b}$ & $57 \mathrm{a}$ & $0.11 \mathrm{~b}$ & $1.4 \mathrm{~b}$ & $3.6 \mathrm{~b}$ \\
\hline 4 weeks & $833 \mathrm{c}$ & $597 \mathrm{~b}$ & $236 \mathrm{~b}$ & $0.28 \mathrm{c}$ & $1.4 \mathrm{~b}$ & $4.5 \mathrm{c}$ \\
\hline \multicolumn{7}{|c|}{ Exp. $2 \mathrm{cv}$. Bintje, standard conditions } \\
\hline 2 weeks & $154 \mathrm{a}$ & $154 \mathrm{a}$ & $0 \mathrm{a}$ & $0.00 \mathrm{a}$ & $0.0 \mathrm{a}$ & $2.0 \mathrm{a}$ \\
\hline 3 weeks & $706 \mathrm{~b}$ & $697 \mathrm{~b}$ & 9 a & $0.01 \mathrm{a}$ & $0.7 \mathrm{~b}$ & $3.4 \mathrm{~b}$ \\
\hline 4 weeks & $1115 \mathrm{c}$ & $917 \mathrm{c}$ & $199 \mathrm{~b}$ & $0.18 \mathrm{~b}$ & $2.2 \mathrm{c}$ & $4.3 \mathrm{c}$ \\
\hline \multicolumn{7}{|c|}{ Exp. 3 cv. Gloria, non-inducing conditions } \\
\hline 2 weeks & $234 \mathrm{a}$ & $234 \mathrm{a}$ & $0 \mathrm{a}$ & $0.000 \mathrm{a}$ & $0.00 \mathrm{a}$ & $2.2 \mathrm{a}$ \\
\hline 3 weeks & $505 \mathrm{~b}$ & $503 \mathrm{~b}$ & $2 a$ & $0.003 \mathrm{a}$ & $0.07 \mathrm{a}$ & $3.9 \mathrm{~b}$ \\
\hline
\end{tabular}

Similar letters within an experiment indicate that differences between means were not significant according to the LSD test ( $\alpha=0.05$; Exps. 1 and 2$)$ or F-test in the ANOVA analysis ( $P \geq 0.05$; Exp. 3$)$

$D W$ dry weight, $H I$ harvest index 
did not differ significantly between the intermediate-age and oldest transplants in $\mathrm{cv}$. Gloria (Exp. 1) but was higher in the oldest transplants in cv. Bintje (Exp. 2).

Also for cv. Gloria raised under non-inducing conditions (Exp. 3), the younger (2-week-old) transplants had lower total and canopy dry weights and a smaller ground cover than the older (3-week-old) transplants at moment of transplanting to the field (Table 1). Tuber formation was successfully delayed in the 3 -week-old transplants raised under non-inducing conditions; there were no significant differences in tuber-related characteristics between 2- and 3-week-old transplants raised under non-inducing conditions.

\section{Field Growth of Transplants Raised Under Standard Conditions (Experiments 1 and 2)}

In crops from transplants raised under standard conditions, significant interaction between transplant age at transplanting (Age) and time after transplanting to the field (DAT) was observed for GC $(P<0.001)$. Younger transplants had a smaller GC after field transplanting but increased more rapidly in GC after transplanting than older transplants (Fig. 1a, b) leading to differences in GC being nullified $\sim 2$ weeks after transplanting and to a higher GC for the younger transplants from $\sim 3$ weeks after transplanting onwards (Fig. 1a, b). This situation was maintained until late in the growing period (cv. Gloria in Exp. 1, Fig. 1a) or until full GC was achieved (cv. Bintje in Exp. 2, Fig. 1b).

Also for canopy (Fig. 1c, d) and tuber dry weights (Fig. 1e, f), significant interactions were found between Age and DAT. Crops from the youngest transplants initially had the lowest dry weights, but the situation was reversed 28 DAT for canopy dry weight and slightly later also for tuber dry weight; differences were maintained until $\sim 70$ DAT in Exp. 1 (Fig. 1c, e) and 42 DAP in Exp. 2 (Fig. 1d, f).

In the first 2 weeks (0-14 DAT) after field transplanting crops from younger transplants grown under standard conditions allocated a higher fraction of the total dry matter produced to canopy growth (instead of tuber growth) than crops from older transplants (Table 2); crops from the oldest transplants even allocated $85-92 \%$ of all dry matter to the tuber fraction. With time after transplanting to the field, the fraction of dry matter allocated to the canopy gradually decreased in crops from young transplants, and it increased in crops from the older transplants. No significant differences in the relative allocation of dry matter between crops from transplants of different ages were observed in the period between 28 and 42 DAT (Table 2).

\section{Field Growth of Transplants Raised Under Non-induced Conditions (Experiment 3)}

No interaction between Age and DAT was found for GC in transplants of cv. Gloria that had been raised under non-inducing conditions (Fig. 2a); the plants from the youngest transplants had a smaller ground cover than those from intermediate-age transplants across the growing period (Fig. 2a). The canopy dry weight in the crop from younger transplants was only significantly lower than that of intermediate-age transplants at transplanting (Fig. 2b). Thereafter, the differences in canopy dry weight seemed to 
Cv. Gloria (Exp. 1)
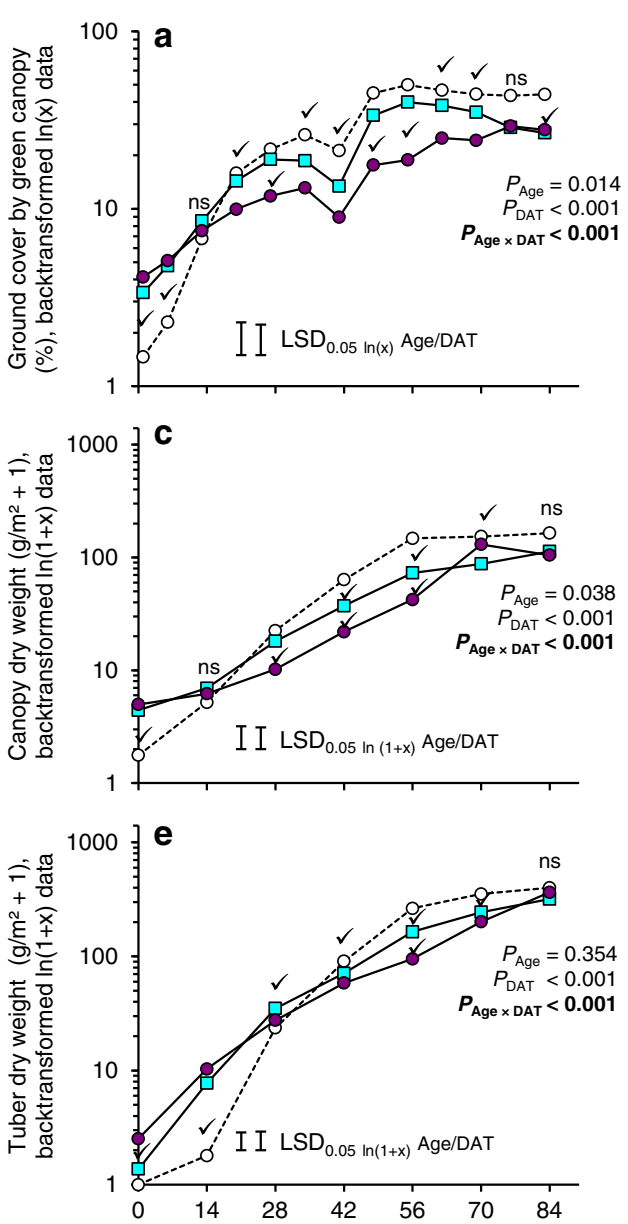

Cv. Bintje (Exp. 2)
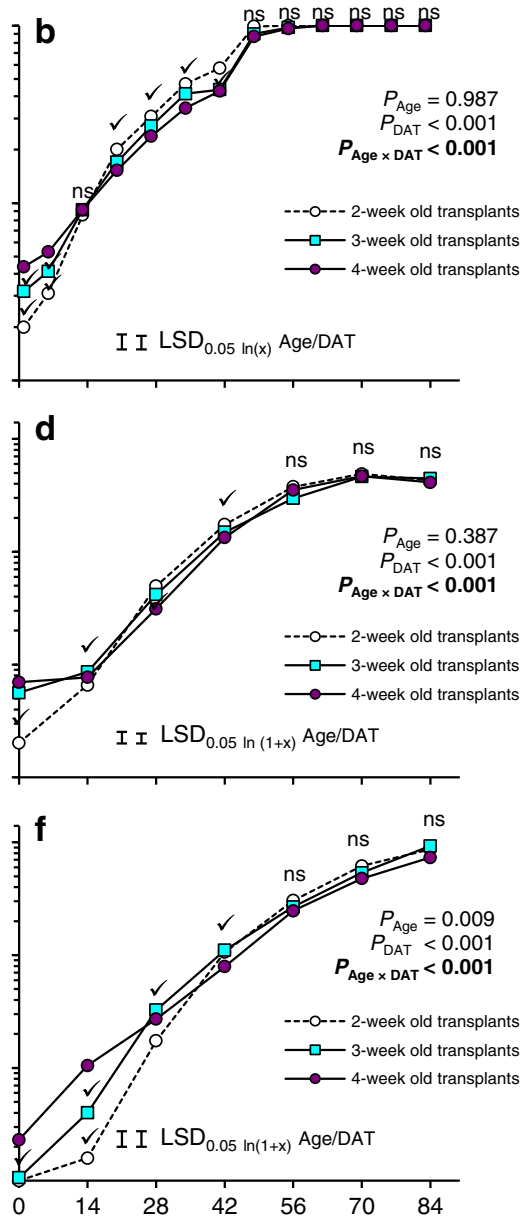

Days after transplanting to the field (DAT)

Fig. 1 Effects of age (Age) of transplants produced under standard conditions on development of ground cover $(\mathbf{a}, \mathbf{b})$, canopy dry weight $(\mathbf{c}, \mathbf{d})$ and tuber dry weight $(\mathbf{e}, \mathbf{f})$ with time after transplanting (DAT) to the field. a, c, e cv. Gloria, Exp. 1. b, d, f cv. Bintje, Exp. 2. Statistical information is based on $\ln (x)$ or $\ln (1+x)$ transformed data. Presented data are backtransformed means. $L S D s$ are for comparisons between different transplant ages (left LSD bar) and for different DAT within a transplant age (right LSD bar). Tick marks inbetween means indicate that those means are significantly different according to the LSD test. Tick marks above the three means indicate the highest mean differs from the lowest, with the intermediate one not differing from either of them. $n s$ indicates that means for the different transplant ages did not differ significantly on that date

persist but were not significant (Fig. 2b). There was no effect of transplant age on tuber dry weight in transplant crops grown under non-inducing conditions (Fig. 2c). Also, no effects of transplant age on dry matter allocation in the first 6 weeks after transplanting were observed for cv. Gloria raised under non-inducing conditions (Table 2, Exp. 3).

Transplants raised under non-inducing conditions, however, had an unsuitable morphology for a seed tuber crop; they had relatively long stems and small leaves, 
Table 2 Proportion of dry matter allocated to the tuber fraction during different time intervals after transplanting to the field of transplants of different age of cv. Gloria (Exp. 1) and cv. Bintje (Exp. 2) raised under standard glasshouse conditions and for transplants of cv. Gloria raised under non-inducing conditions in growth rooms (Exp. 3)

Age of transplant at field transplanting

Proportion dry matter to tubers \%

\begin{tabular}{ll}
$0-14$ DAT $\quad$ 28-42 DAT \\
\hline
\end{tabular}

Exp. 1 cv. Gloria, standard conditions

$\begin{array}{llll}2 \text { weeks } & 20(80) \mathrm{a} & 56(44) \mathrm{a} & 63(37) \mathrm{a} \\ 3 \text { weeks } & 73(27) \mathrm{b} & 70(30) \mathrm{ab} & 62(38) \mathrm{a} \\ 4 \text { weeks } & 85(15) \mathrm{b} & 84(16) \mathrm{c} & 73(27) \mathrm{a}\end{array}$

Exp. 2 cv. Bintje, standard conditions

$\begin{array}{llll}2 \text { weeks } & 12(88) \mathrm{a} & 26(73) \mathrm{a} & 42(58) \mathrm{a} \\ 3 \text { weeks } & 49(51) \mathrm{b} & 46(54) \mathrm{b} & 42(58) \mathrm{a} \\ 4 \text { weeks } & 92(8) \mathrm{c} & 40(60) \mathrm{ab} & 34(66) \mathrm{a} \\ \text { Exp. } 3 \mathrm{cv} \text {. Gloria, non-inducing conditions } & & & \\ 2 \text { weeks } & 21(79) \mathrm{a} & 59(41) \mathrm{a} & 61(39) \mathrm{a} \\ 3 \text { weeks } & 30(70) \mathrm{a} & 54(46) \mathrm{a} & 45(55) \mathrm{a}\end{array}$

Similar letters within an experiment indicate that differences between means were not significant according to the LSD-test ( $\alpha=0.05$; Exp. 1 and 2 ) or F-test in the ANOVA analysis ( $P \geq 0.05$; Exp. 3$)$. Between parentheses: the remaining proportion dry matter allocated to the canopy

were unsuitable for rouging and were susceptible to wind during the later field growth. Because they were primarily raised to be able to evaluate transplants of different age without a concomitant pronounced difference in the degree of tuber induction, they were only used to assess differences in ground cover and dry matter production and allocation in different plant parts and not considered in the full yield formation analysis later in this paper.

\section{Yield Formation in Crops from in Transplants Raised Under Standard Conditions}

Radiation Interception During the Field Period For AIR, interaction between Age and DAT was significant in the experiments where transplants were raised under standard conditions (Fig. 3a, b). The AIR was lower in crops from the youngest transplants than in crops from the oldest transplants at 14 DAT, but at 28 DAT, the situation was reversed. This lasted until the end of the growing period in Exp. 1 (Fig. 3a); in Exp. 2 (Fig. 3b), differences were not significant anymore at the later sampling dates. Crops from intermediate-age transplants had an intermediate radiation interception that was not significantly different from that in crops of the youngest or the oldest transplants or both (Fig. 3a, b).

Dry Matter Production During the Field Period Also, for TDW production during the field period, interaction between Age and DAT was significant in both experiments (Fig. 3c, d). The TDW production during the field period was lower in crops from the youngest transplants than in crops from the oldest transplants at 14 DAT; this was fully 
Cv. Gloria (Exp. 3)

non-inducing conditions during transplant production

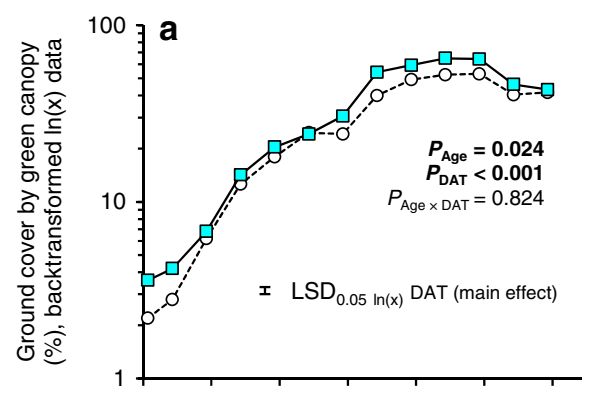

--- 2-week old transplants

$\longrightarrow$ 3-week old transplants

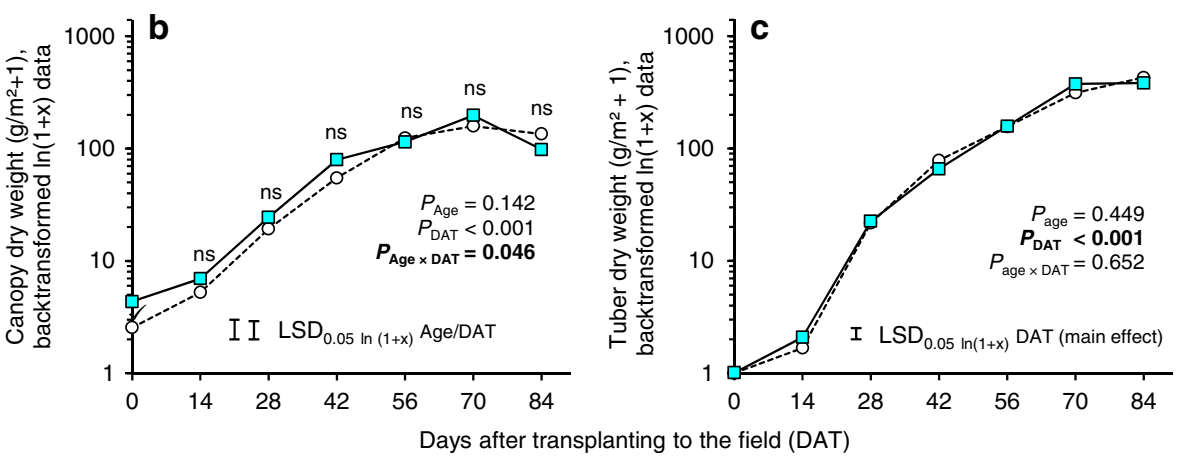

Fig. 2 Effects of age (Age) of transplants produced under non-inducing conditions on development of ground cover (a), canopy dry weight (b) and tuber dry weight (c) with time after transplanting (DAT) to the field. Statistical information is based on $\ln (x)$ or $\ln (1+x)$-transformed data. Presented data are backtransformed means. In case of interaction, the LSDs are for comparisons between different transplant ages (left LSD bar) and for different DAT within a transplant age (right LSD bar). For explanation of tick marks, see Fig. 1

reversed at 28 DAT in Exp. 2 and slightly later in Exp. 1. The TDW production remained higher in crops from the youngest transplants than in crops from the oldest transplants until the end of the growing period in cv. Gloria, Exp. 1 (Fig. 3c), and until 42 DAT in cv. Bintje, Exp. 2 (Fig. 3b), after which differences became non-significant in Exp. 2. Crops from intermediate-age transplants usually took an intermediate position, not differing in total dry matter production from crops from the youngest and/or the oldest transplants.

Radiation Use Efficiency During the Field Period Radiation use efficiency (RUE), i.e. the efficiency by which crop dry matter was produced from the total radiation intercepted by the crop during the field period, increased clearly with time after transplanting, when the interval over which it was calculated increased in length (Fig. 3e, f). The RUE was not affected by transplant age in Exp. 2 and not systematically affected by transplant age in Exp. 1, where interaction between Age and DAT was significant; in this experiment, crops from the youngest transplants seemed to reach their maximum values earlier than crops from the oldest transplants, which seemed to increase in efficiency longer in time. When TDW production during the field period is plotted against AIR in time (Fig. 3g, h) differences in efficiency of radiation conversion during different time intervals are shown. The shallow slopes of the lines connecting 
Cv. Gloria (Exp. 1)
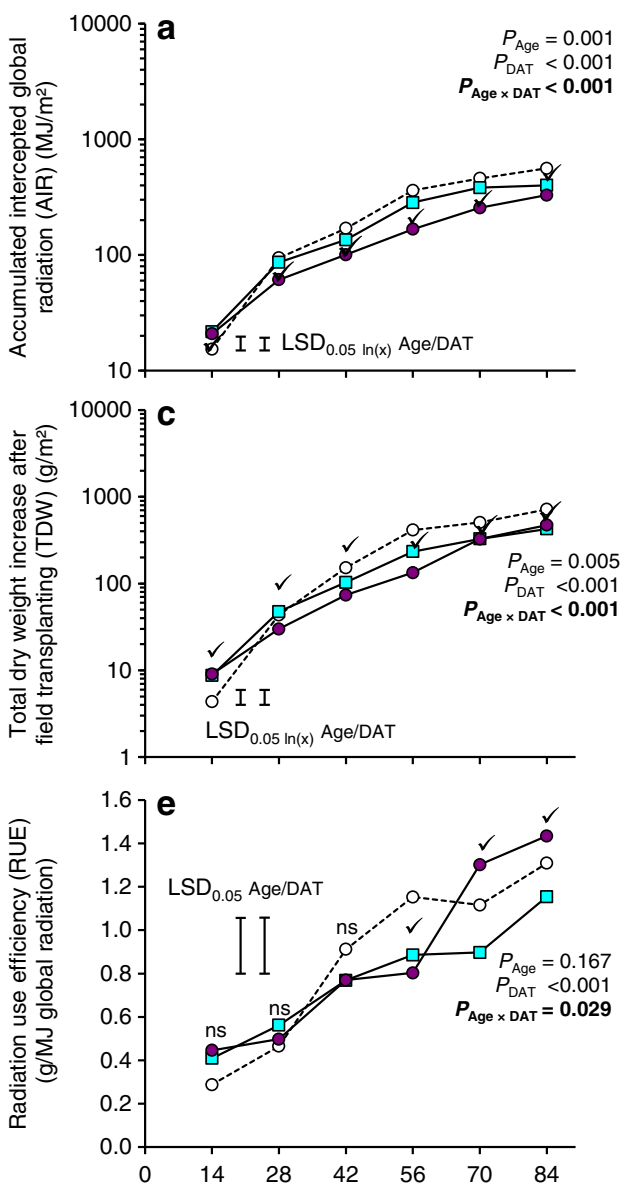

Days after transplanting to the field (DAT)

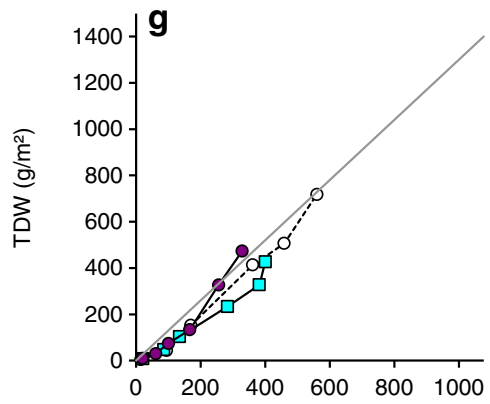

Cv. Bintje (Exp. 2)

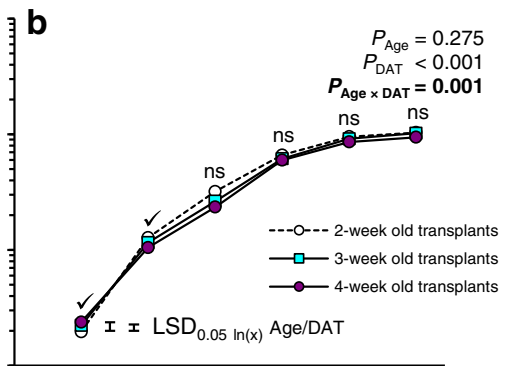

d
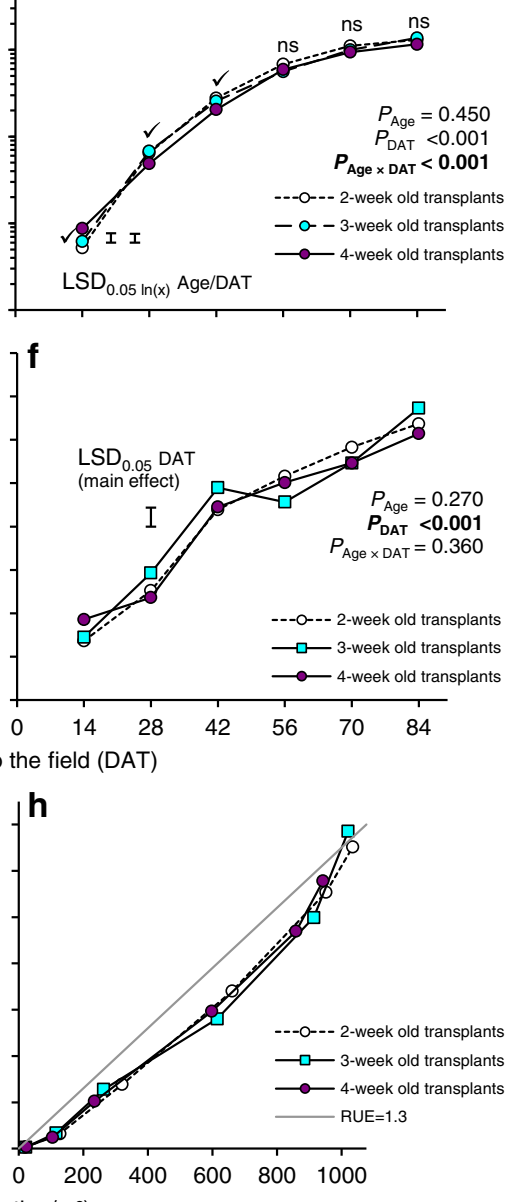

Fig. 3 Effects of age (Age) of transplants produced under standard conditions on AIR (a, b), TDW (c, d) and RUE (e, f) during field growth (DAT), and the association between AIR and TDW (g, h). a, c, e, g cv. Gloria, Exp. 1. b, d, f, h cv. Bintje, Exp. 2. Statistical information in (a)-(d) based on $\ln (x)$-transformed data; presented data are backtransformed means. In case of interaction, the LSDs are for comparisons between different transplant ages (left LSD bar) and for different DAT within a transplant age (right LSD bar). For explanation of tick marks, see Fig. 1 
the points at the low AIR levels at the early sampling dates indicate a low efficiency for crops from all transplant ages regardless of their AIR level, whereas crops from all transplant ages became more efficient at the higher AIR levels later in the growing period.

Harvest Index The HI indicates which fraction of the total dry matter produced (during both the transplant production period and the field period) was allocated to the tubers. There was significant interaction between Age and DAT for HI in both experiments (Fig. 4). Older transplants at the moment of transplanting had a higher HI than younger transplants (Table 1 and Fig. 4), and this HI increased further in the first 14 days after transplanting in all treatments in both experiments (Fig. 4), with differences between crops from different transplant ages becoming even more pronounced. Thereafter, HI increased gradually with time after transplanting in crops from the youngest transplants, whereas in crops from intermediate-age transplants, the increase was slowed down and then arrested until the moment in time that the HI in crops from the younger transplants had increased to a comparable height; from then onwards, HI increased at the same rate in crops from intermediate-age transplants as in crops from the youngest transplants. In crops from the oldest transplants, HI after the initial strong increase was reverted to a decrease, down to the level of the younger transplants or even to a lower level in Exp. 1. Thereafter, also in the crops from the oldest transplants, HI again increased. Crops from young transplants had a significantly lower HI than crops from older transplants up to 42 DAT in Exp. 1 and 28 DAT in Exp. 2, whereas their HI was significantly higher than that of the oldest transplants at 70 DAT in Exp. 1.

Fresh Tuber Yield For fresh tuber yield, interaction between Age and DAT was significant in both experiments (Fig. 5a, b). In both experiments, fresh tuber weights were lower for crops from younger transplants at 14 DAT, whereas differences were not significant anymore at 28 DAT. Thereafter, tuber yields became higher in crops from younger transplants in cv. Gloria (Exp. 1) which was maintained during the major part of the later growing period (Fig. 5a) with crops from intermediate-age transplants taking a position that usually did not differ from the youngest and/or the oldest

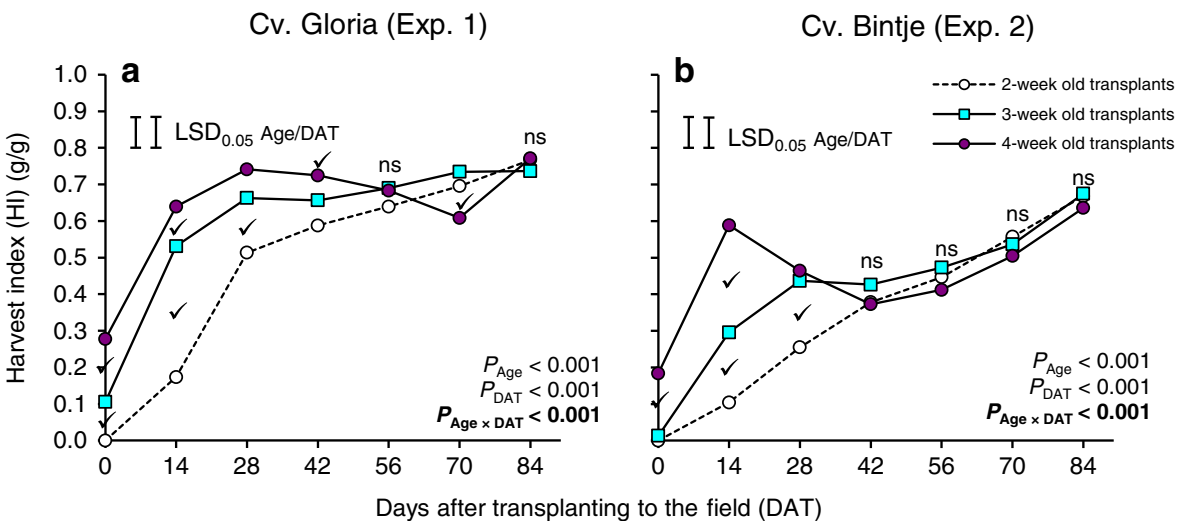

Fig. 4 Effects of age (Age) of transplants produced under standard conditions on development of HI with time after transplanting (DAT) to the field. a cv. Gloria, Exp. 1. b cv. Bintje, Exp. 2. LSDs are for comparisons between different transplant ages (left LSD bar) and for different DAT within a transplant age (right LSD bar). For explanation of tick marks, see Fig. 1 
Cv. Gloria (Exp. 1)
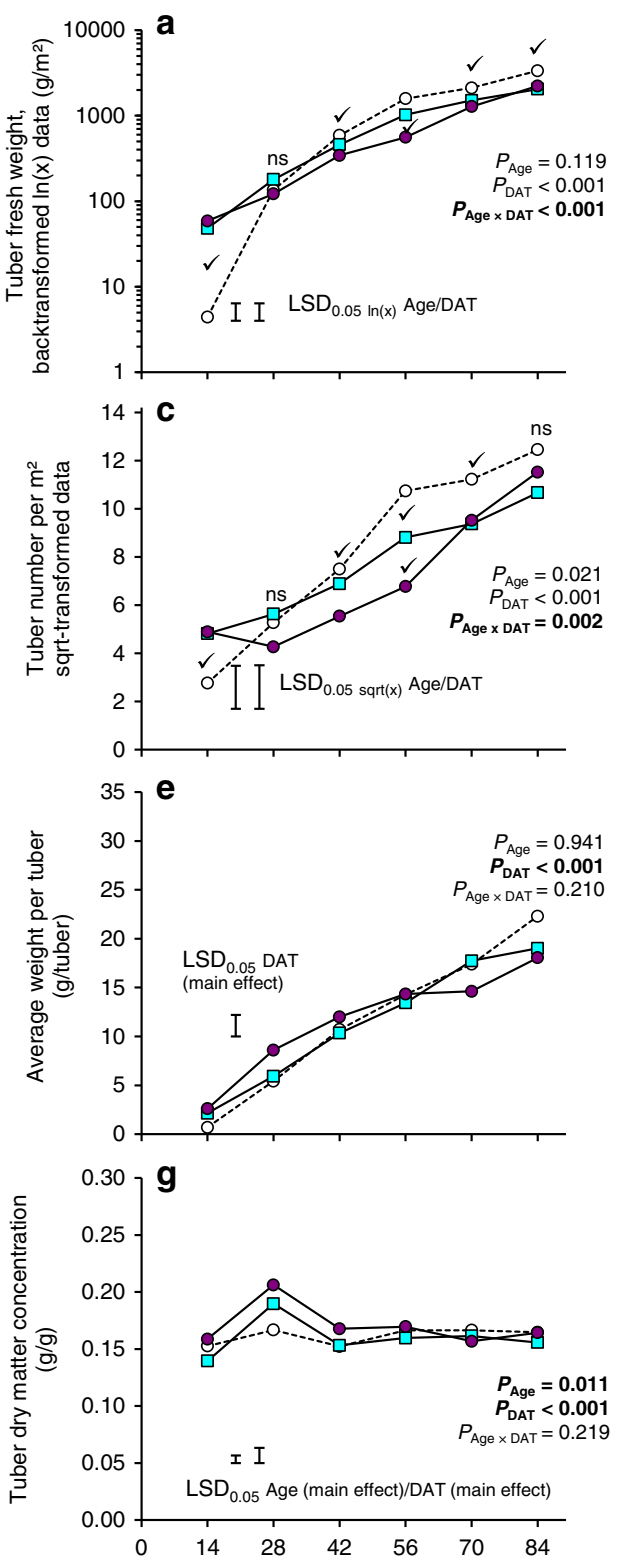

Cv. Bintje (Exp. 2)
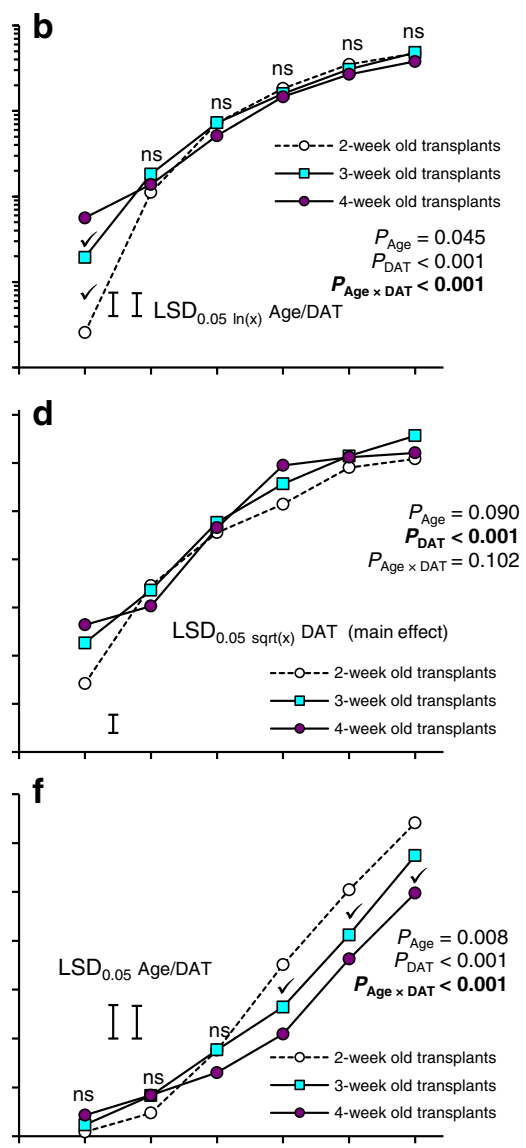

h

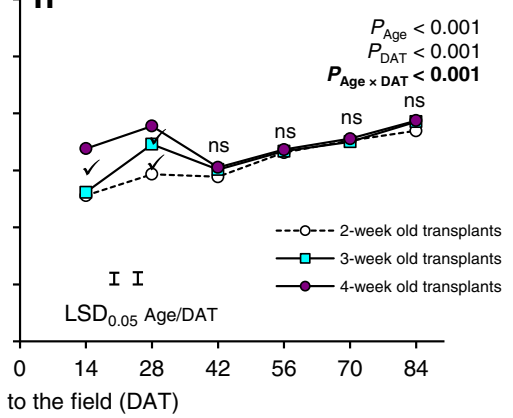

Fig. 5 Effects of age (Age) of transplants produced under standard conditions on development of tuber fresh weight $(\mathbf{a}, \mathbf{b})$, tuber number (square root-transformed data; $\mathbf{c}, \mathbf{d})$ and weight per tuber $(\mathbf{e}, \mathbf{f})$ and tuber dry matter concentration (g, h) with time after transplanting (DAT) to the field. a, c, e, $\mathbf{g}$ cv. Gloria, Exp. 1. b, d, f, h cv. Bintje, Exp. 2. Statistical information in (a) and (b) is based on $\ln (x)$-transformed data. Presented data are backtransformed means. In case of interaction, the LSDs are for comparisons between different transplant ages (left LSD bar) and for different DAT within a transplant age (right LSD bar). For explanation of tick marks, see Fig. 1

transplants. In cv. Bintje (Exp. 2), the same trend was observed, but differences between transplant ages were not significant from 28 DAT onwards (Fig. 5b). 
Tuber Number Significant interaction between Age and DAT was found in Exp. 1 (Fig. 5c); tuber number was lowest in crops from the youngest transplants at 14 DAT, not significantly different between crops from different transplant ages at 28 DAT and thereafter became higher in crops from the youngest transplants than in crops from the oldest transplants during the major part of the later growing season, but not at the last sampling date, 84 DAT. There was no effect of transplant age on tuber number in Exp. 2 (Fig. 5d).

Weight per Tuber The average weight per tuber increased during the growing period but was not affected by the transplant age in Exp. 1. In Exp. 2, significant interaction between Age and DAT occurred due to insignificant differences in weight per tuber between crops from different transplant ages in the first part of the field period, but a higher weight per tuber in the crop from the youngest transplants than in crops from older transplants during the later part of the field period.

Tuber Dry Matter Concentration Tuber dry matter concentration was slightly higher in crops from the oldest transplants than in crops from younger transplants in Exp. 1 across the full period (due to the absence of significant interaction between Age and DAP). In Exp. 2, where significant interaction occurred, the higher concentration in crops from older transplants was only visible in the first part of the growing period, whereas differences in tuber dry matter concentration between transplant ages were not significant anymore in the last part of the growing period.

\section{Discussion}

\section{The State of Transplants at Field Transplanting}

In vitro potato plantlets are suggested not to be induced to form tubers at the moment they are planted out in glasshouses, but to progress towards an induced stage soon thereafter (Lommen and Struik 2006). When raised under standard glasshouse conditions, older transplants indeed were more advanced in the tuber formation process than younger transplants at the moment transplanting to the field, as shown by higher (if any) tuber dry weights and a higher harvest index at that moment (Table 1). When transplants of cv. Gloria were raised under artificial, non-inducing conditions (Exp. 3), tubers were hardly present at field transplanting and differences in tuber-related parameters were not significant, suggesting that the tuber formation process was delayed under these conditions.

Older transplants, regardless of the conditions under which they were produced, were more advanced in growth and canopy development than younger transplants at the moment of transplanting to the field and usually had a higher GC at field planting (Table 1). This indicates a potentially better radiation interception, since the GC and radiation interception are directly related in potato crops (e.g. Haverkort et al. 1991b).

\section{Dry Matter Allocation During the Field Period}

Dry matter allocation was the crucial process determining the performance of crops from transplants of different age when produced under standard conditions. In the first 
weeks after field transplanting, crops from older transplants allocated a higher percentage of the DM produced to tuber growth than crops from younger transplants (Table 2). This limited the DM allocation to the canopy. Consequently, crops from older transplants increased slower in ground cover than crops from younger transplants (Fig. 1a, b) and became inferior to them in radiation interception and production $\sim 3-4$ weeks after field transplanting (Fig. 3a-d). At that time, the initial order in performance of crops from transplants of different age was reversed in both experiments.

During later field growth, the unfavourable dry matter allocation in crops from older transplants was gradually reverted and normalized. The normalization of the pattern occurred earlier in crops from intermediate-age transplants than in crops from the oldest transplants, and earlier in cv. Bintje (Exp. 2) than in cv. Gloria (Exp. 1) (Fig. 4); this is in line with the degree to which these crops would have advanced in the tuber formation process at transplanting.

All of the above resulted in highly significant interactions $(P<0.001)$ between transplant age (Age) and time after field planting (DAT), for almost all productionrelated variates (GC, AIR, weights of total and different fractions, HI) of crops from transplants grown under standard conditions, indicating that the effect of the transplant age on crop performance changed in time. This was not found when transplants were raised under the artificial, non-inducing conditions in Exp. 3, re-stressing the importance of the degree to which the transplants would have advanced in the tuber formation process at the moment of transplanting to the field.

\section{Using Younger Transplants Will Favour Tuber Yield}

Although less advanced at the moment of transplanting to the field, crops from younger transplants produced higher fresh tuber yields than crops from older transplants in the later part of the growing period in Exp. 1 (Fig. 5a); the same trend was observed in Exp. 2 where, however, the differences in the (transformed) fresh tuber yields between transplant crops of different ages were too small to be significant during the last part of the growing period (Fig. 5b). At 70 DAT, the harvest date closest to when the canopy of a high grade seed crop would have been destructed, the (untransformed) yield levels (all tubers $>0 \mathrm{~mm}$ ) were 22.9, 15.3 and $13.8 \mathrm{Mg} /$ ha for the crops from 2-, 3- and 4week-old transplants raised under standard conditions, respectively, in Exp. 1, and 35.1, 30.9 and $29.3 \mathrm{Mg} /$ ha for the respective treatments in Exp. 2 (data not shown). The higher fresh tuber yields in crops from younger transplants were achieved through a higher tuber number in Exp. 1, with the average weight per tuber not being significantly affected (Fig. 5c, e), whereas in Exp. 2, crops from younger transplants had a slightly higher average weight per tuber than those from older transplants (Fig. 5f) without significant effects on yield.

\section{Yield Formation Analysis}

A yield formation analysis was carried out (e.g. van der Veeken and Lommen 2009, based on Haverkort and Harris 1987 and MacKerron and Waister 1985) to assess which of the variates underlying tuber fresh weight in the later field stage (AIR, RUE, HI and dry matter fraction of the tubers) were affected by transplant age and which not. 


\section{Ground Cover Was the Main Driver for Differences in Radiation Interception and}

Tuber Yield The daily radiation interception is the result of the incident radiation level and the fraction of the radiation intercepted by the crop on that day. Because transplants from different ages were transplanted on the same day to the field, the main driver for differences in radiation interception in all experiments was the GC, not differences in daily incident radiation levels.

Younger transplants had a smaller GC after field transplanting (Table 1), but because they allocated a higher fraction of the DM produced in the first weeks after field transplanting to canopy growth than older transplants (Table 2), they increased more rapidly in GC than older transplants (Fig. 1a, b). Consequently, GC was higher in crops from the youngest transplants than in crops from the oldest transplants $\sim 3$ weeks after transplanting (Fig. 1a, b). This situation was maintained until late in the growing period for cv. Gloria (Exp. 1; Fig. 1a). Full GC was never achieved in cv. Gloria, and crops from older transplants in this cultivar achieved later and lower maximum GC, leading to AIR and TDW production being significantly higher in crops from younger transplants during the remaining field period. In cv. Bintje (Exp. 2), differences in GC between age classes were smaller than in Exp. 1 and GC was only affected by transplant age until full ground cover was achieved $\sim 7$ weeks after transplanting (Fig. 1b). Consequently, differences in radiation interception and production due to transplant age could not be assessed as significant in the later part of the field period in Exp. 2.

\section{RUE Changed with Time but Was Not Directly Affected by Transplant Age The} RUE expresses the efficiency by which a crop converts the intercepted radiation into dry matter; it was calculated by dividing the TDW production of a plot at a sampling date by the AIR intercepted by the crop in that plot. The RUE calculated is therefore based on the total interception and production until that moment. There was a marked increase in RUE with time after field planting (Fig. 3e, f), which suggests that field production was severely limited in the early stages after field transplanting. With time, more dry matter was produced more efficiently, leading to 'dilution' of the early effects. This is clearly shown in Fig. $3 \mathrm{~g}$, h, which presents the associations between AIR and TDW production (the variates underlying RUE) during the growing period. The steeper slopes of the lines connecting the points in Fig. $3 \mathrm{~g}, \mathrm{~h}$ at the higher AIR levels for a treatment confirm that the conversion of the intercepted radiation was most efficient at the end of the growing period. This could be caused by less stressful conditions, tuber dry matter being more efficiently produced than leaf dry matter, increase in photosynthesis level because of the presence of strong tuber sinks, or by a slightly lower radiation intensity later in the field period.

There was no evidence that crops from older transplants differed strongly in RUE from crops from younger transplants; transplant age had no effect on RUE in Exp. 2 and no meaningful effect in Exp. 1. Moreover, Fig. $3 \mathrm{~g}$, h shows that the slopes of all age treatments were perfectly in line during the early time intervals after field planting, with the location of the lines being mainly affected by the differences in AIR - caused by differences in GC - between age treatments. The seemingly strong increase in RUE in crops from the oldest transplants at the last sampling dates in Exp. 1 (Fig. 3e) was due to their very low radiation interception and dry weight production until late in the growing period (Figs. 1a and 3a, e); these hardly contributed to total radiation interception and production during the last period when the crop grew effectively (Fig. 3g). 
Harvest Index Was of Minor Importance for Explaining Yield Differences at the End of the Field Period but an Important Indicator of Undesirable Dry Matter Allocation During the Early Field Period In a yield formation analysis, a high $\mathrm{HI}$ at the end of the growing period indicates a mature crop in which a high fraction of the total dry matter has been allocated to the parts that are harvested. In the last part of the growing period in the experiments, the HI (Fig. 4) was usually not significantly different anymore between different transplant age classes (except at 70 DAT in Exp. 1 where the oldest transplants had the lowest HI; Fig. 4a) and as such did not or hardly contribute to differences in tuber weight.

On the other hand, the high HIs found early after field planting in crops from older transplants produced under standard conditions (Fig. 4) were indicative of the undesirable dry matter allocation pattern in these crops and a major determinant limiting radiation interception in the phase before canopy closure. They resulted from the very high proportion of dry matter allocated to tuber growth by these crops (85-92\% for the oldest transplants, Table 2) which severely restricted the canopy growth (Fig. 1c, d) and thereby limited the yield potential.

The HI is the resultant of the partitioning processes until the moment the $\mathrm{HI}$ is established. During a growing period, a change in $\mathrm{HI}$ indicates that the relative growth rates of the tuber and canopy fraction are different. In potato crops grown from tubers, HI increases with time after tuber initiation until crop senescence (e.g. Neele 1990). A consistently increasing HI (reflecting a consistently higher relative growth rate of the tuber fraction than of the canopy fraction) was only found in crops from the youngest transplants (Fig. 4). In crops from older transplants, the unfavourable dry matter allocation early after field planting was gradually reverted, as shown by the check in increase of HI in crops from intermediate-age transplants and decreasing HIs in crops from the oldest transplants (Fig. 4).

Differences in Tuber Dry Matter Concentration Are of Minor Importance for Explaining Fresh Tuber Yield in the Last Part of the Field Period Tuber dry matter concentration was higher in crops from the oldest transplants than in crops from the youngest transplants early in the growing period of Exp. 2 (Fig. 5h), and across all sampling dates in Exp. 1 (only main effects were significant in Exp. 1; Fig. 5g); however, also in Exp. 1, differences were found mainly in the first part of the growing period (Fig. 5g). Therefore, differences in tuber dry matter concentration during the last part of the field period were not relevant for explaining differences in final tuber yield.

\section{Implications for Transplant Production Management}

The research described in this paper was primarily directed at improving understanding and not at giving recommendations. Nevertheless, the results show clearly that transplant crops from younger transplants (in this case, 2-week-old transplants) will perform better after transplanting to the field than crops from older transplants - or at least perform at par. They also suggest that especially transplants from very early cultivars may give crop failure when they are already too advanced in the tuber formation process at the end of the transplant production period. This needs to be reverted in the field phase in order to produce a successful crop or should be avoided by transplant 
production management directed towards a low (tuber) induction state at the moment of field planting. The induction state of transplants at the moment of transplanting is determined by the genotype and the duration of the transplant production phase, but also by the environmental conditions and the management during transplant production and their interactions (see Lommen and Struik 2006 for interactions between $\mathrm{G} \times \mathrm{D} \times \mathrm{E}$ ). Also, the status of the in vitro plantlets used could potentially affect the performance (Tadesse et al. 2001c). in the present research, the latter was ensured to be as equal as possible between treatments by using in vitro plantlets of the same age for transplant production. The environment and management during transplant production will become especially critical when transplant production has to last more than 2 weeks, e.g. for logistical reasons; this is because environmental effects on tuber induction and formation become only apparent after more than $\sim 2$ weeks, as shown for tuber induction and initiation by Lommen and Struik (2006) and for tuber formation by the non-significant effect of transplant age in Exp. 3 as compared to the effect in Exp. 1 (Table 1).

The results imply that the very early cultivars may need most attention during commercial transplant production because they are most prone to become too advanced in tuber formation. They therefore should get short transplant production periods, when possible conditions that are not inductive for tuber production and they probably could be among the last transplants to be produced and planted out in spring. Late production will ensure that photoperiods during production are relatively longer and soil temperatures relatively higher than at the moment the first transplants are produced and transplanted to the field. This may additionally avoid too early tuber initiation and bulking.

Acknowledgments I greatly acknowledge the role of Mr. M. van Soesbergen, who carried out the experiments as part of his MSc study. I also thank the phytotron and field assistants of Wageningen University involved in this work for their enthusiasm in producing the thousands of transplants and growing the field crops.

Open Access This article is distributed under the terms of the Creative Commons Attribution 4.0 International License (http://creativecommons.org/licenses/by/4.0/), which permits unrestricted use, distribution, and reproduction in any medium, provided you give appropriate credit to the original author(s) and the source, provide a link to the Creative Commons license, and indicate if changes were made.

\section{References}

Dixon TJ (1993) The role of micropropagation in the production of tubers for variety testing. Potato Res 36 : $377-378$

Farran I, Mingo-Castel AM (2006) Potato minituber production using aeroponics: effect of plant density and harvesting intervals. Am J Potato Res 83:47-53

Hagman J (1990) Micropropagation of potatoes. Comparison of different methods. Crop Prod Sci 9:31-80

Haverkort AJ, Harris PM (1987) A model for potato growth and yield under tropical highland conditions. Agric For Meteorol 39:271-282

Haverkort AJ, van de Waart M, Marinus J (1991a) Field performance of potato minitubers as propagation material. Potato Res 34:353-364

Haverkort AJ, Uenk D, Veroude H, van de Waart M (1991b) Relationships between ground cover, intercepted solar radiation, leaf area index and infrared reflectance of potato crops. Potato Res 34:113-121

Jones ED (1988) A current assessment of in vitro culture and other rapid multiplication methods in North America and Europe. Am Potato J 65:209-220 
Levy D (1988) Propagation of potato by the transfer of transplants of in vitro proliferated shoot cuttings into the field. Sci Hortic 36:165-171

Li W, Zhu X, Chen Y (1990) Rapid propagation of potato minituber and the system of seed improvement for potato early cultivar. J Potato 4:201-205

Lommen WJM (1999) Causes for low tuber yields of transplants from in vitro potato plantlets from early cultivars after field planting. J Agric Sci (Camb) 133:275-284

Lommen WJM, Struik PC (1992) Production of potato minitubers by repeated harvesting: effects of crop husbandry on yield parameters. Potato Res 35:419-432

Lommen WJM, Struik PC (2006) Tuber induction and initiation during production and early field growth of transplants from in vitro-derived potato plants. Ann Appl Biol 149:281-290

MacKerron DKL, Waister PD (1985) A simple model of potato growth and yield. Part I. Model development and sensitivity analysis. Agric For Meteorol 34:241-252

Mc Cown BH, Wattimena GA (1987) Field performance of micropropagated potato plants. Biotechnol Agric For 3:80-88

Murashige T, Skoog F (1962) A revised medium for rapid growth and bio assays with tobacco tissue cultures. Physiol Plant 15:473-497

Neele AEF (1990) Study on the inheritance of potato tuber yield by means of harvest index components and its consequences for choice of parental material. Euphytica 48:159-166

Ritter E, Angulo B, Riga P, Herrán C, Relloso J, San Jose M (2001) Comparison of hydroponic and aeroponic cultivation systems for the production of potato minitubers. Potato Res 44:127-135

Sipos J, Nowak J, Hicks G (1988) Effect of daminozide on survival, growth and yield of micropropagated potatoes. Am Potato J 65:353-364

Struik PC (2007) The canon of potato science: 25. Minitubers. Potato Res 50:305-308

Struik PC, Lommen WJM (1990) Production, storage and use of micro- and minitubers. In: Proceedings 11th Triennial Conference of the European Association for Potato Research, Edinburgh, UK, pp 122-133

Struik PC, Wiersema S (1999) Seed potato technology. Wageningen, Wageningen Pers

Tadesse M, Lommen WJM, Struik PC (2001a) Effect of nitrogen pre-treatment of transplants from in vitro produced potato plantlets on transplant growth and yield in the field. Neth J Agric Sci 49:67-79

Tadesse M, Lommen WJM, Struik PC (2001b) Effect of temperature pre-treatment of transplants from in vitro produced potato plantlets on transplant growth and yield in the field. Potato Res 44:173-185

Tadesse M, Lommen WJM, Struik PC (2001c) Development of micropropagated potato plants over three phases of growth as affected by temperature in different phases. Neth J Agric Sci 49:53-66

Thornton MK, Knutson KW (1986) Effect of transplant container volume and growing season length on field performance of micropropagated potatoes. Am Potato J 63:399-412

van der Veeken AJH, Lommen WJM (2009) How planting density affects number and yield of potato minitubers in a commercial glasshouse production system. Potato Res 52:105-119 